POLIIICAL ECONOMY RESEARCH INSIITUTE

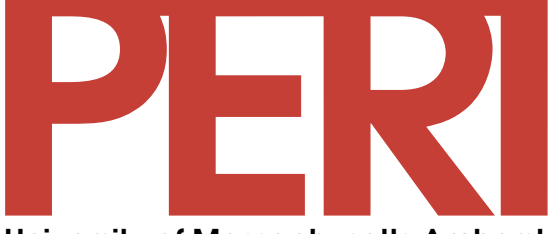

University of Massachusetts Amherst

\title{
Economic Integration, Cultural Standardization, and the Politics of Social Insurance
}

\author{
Samuel Bowles \\ Ugo Pagano
}

2003

10th floor Thompson Hall University of Massachusetts Amherst, MA, 01003-7510 Telephone: (413) 545-6355 Facsimile: (413) 545-2921

Email:peri@econs.umass.edu Website:

http://www.umass.edu/peri/

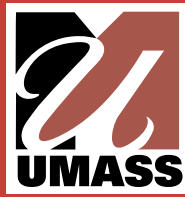


ECONOMIC INTEGRATION, CULTURAL STANDARDIZATION, AND THE POLITICS OF SOCIAL INSURANCE

Samuel Bowles and Ugo Pagano

21 July, 2003 


\section{Introduction}

Does the freer movement of goods, people, ideas and money across national boundaries mean that, as Charles Kindleberger (1969):207 put it, "the nation state is just about through as an economic unit" when it comes to the provision of social insurance and programs of egalitarian redistribution? Surely globalization will not eliminate the conditions - economic insecurity and distributions of income widely thought to be unfair - that initially gave rise to the welfare state. What form will responses to these conditions take in a globally integrated economy?

The thesis we will advance is this. ${ }^{1}$ Globalization is an extension of nationalism (not its antithesis) with regard to some aspects of culture and economic structure: it promotes cultural standardization and economic integration across national boundaries. But unlike nationalism, globalization does this without providing either the international cultural solidarity or governmental institutions capable of supporting egalitarian redistribution and insurance on a global scale, while weakening the nation-based institutions for the same. In this respect a globalized world may recreate the social structure of the archetypal agrarian empire: a dominant English-speaking class of cosmopolitans presiding over a heterogeneous and provincial underclass speaking a Babel of dialects, with little solidarity across the language groups and weak nationallybased instruments of social insurance and egalitarian redistribution.

The politics of social insurance may thus increasingly pit the cosmopolitans against the provincials (not capital against labor, or even the high earners against the low earners, as many of the cosmopolitans are far from rich.) The result need not be institutional convergence to a world of uniformly minimalist welfare states, however, for the process of specialization induced by greater integration may support distinct institutional arrangements appropriate to each economy's divergent product mixes. Countries specializing in goods characterized by volatile demand or requiring high levels of specific skills may be induced by globalization to strengthen their systems of

1 To appear in Bardhan, Bowles, and Wallerstein (2004). We have benefitted from the comments of participants at the Workshop on Globalization and Egalitarian Distribution at the Santa Fe Institute, May 16-18, 2002 and Massimo D' Antoni, Pranab Bardhan, Franco Belli, Marianna Belloc, Michele Di Maio Michael Wallerstein and Elisabeth Wood. Authors' affiliations: Pagano, University of Siena and Central European University; Bowles, University of Siena and Santa Fe Institute. We would like to thank the MacArthur Foundation, the Santa Fe Institute and the PAR funding of the University of Siena for support of this research. The authors may be contacted at pagano@unisi.it and bowles@ santafe.edu or http://www.santafe.edu / bowles 
social protection.

It is likely, however, that in many countries the reverse will occur. In these economies, social insurance will be compromised, leaving the provincials increasingly vulnerable to industry- or occupation-specific shocks. Where this occurs, risk reduction may take the form of foregoing specialization in occupation- or industry-specific skills, and maintaining a relatively unspecialized national "portfolio" of sectors and occupations to which one may move if one's own source of livelihood is threatened.

In this case, optimal integration into the global order requires balancing the marginal gains in expected income associated with greater specialization (the gains from trade) against the marginal losses associated with the enhanced risks occasioned by specialization. This optimum will not be achieved by private decision-making, because the availability of a diverse portfolio of sectors and occupations has a public good aspect.

We advance this thesis not as the confirmed result of a coherent model adequately tested empirically, but rather as a research agenda that is not inconsistent with what is known, and worth pursuing in light of the importance of the issues it addresses.

\section{Globalization: the Highest Stage of Nationalism?}

Globalization is typically represented by economists as the process of integration of national economies brought about by the reduction in costs of transportation and communication and the removal of impediments to the movement of goods, people and finance across national borders. But the same processes that have fostered the freer movement of goods, people, and finance are also creating a global culture, that is a common language and system of meanings among people in many nations.

Ernest Gellner (1983) defined nationalism as a movement seeking congruence between the ethnic community and the political community: "one national state, one national culture!" has been its political motto. ${ }^{2}$ Because we are going to claim that globalism is an extension of Gellner's nationalism, we will consider his interpretation in some detail:

...nationalism is a theory of political legitimacy which requires that ethnic boundaries should not cut across political ones and in particular that ethnic boundaries withing a given state...should not separate the power holders from the rest. (Gellner (1983):1)

${ }^{2}$ His later works (Gellner (1998;(1999)) recognized the continuity between nationalism and globalism. See also Pagano, U. (2003) 
The standardization of language and culture within a nation that nationalism sought and largely accomplished is what made it so radical during its early years, especially by comparison with the structure of the agrarian empires and other agrarian societies that it replaced.

The technological stagnation of agrarian society allowed the endless repetition of the same production process; individuals could perpetuate the same jobs based on the same skills from one generation to the next. Cultural diversity among all except the elite stabilized these roles. It limited both horizontal and vertical mobility and allowed the endless reproduction of the social fabric over time. Cultural diversity -- both between the elite and the rest, and among the rest -- was both a condition for and a result of societal inertia. It supported the stagnation of society by depriving most of its members of the incentives to seek social mobility. At the same time cultural diversity along both its horizontal and vertical dimensions favored by the unchanging structure of society.

The rudimentary and geographically confined division of labor in these societies was such that ordinary farmers and craftsmen in one locality had little need to communicate with their counterparts in other locales. Other than the payment of taxes or the transfer of a share of their crops, they had even less need to interact with members of the elite.

But the broadening scope of goods markets and eventually the emergence of labor markets and other capitalist economic institutions radically altered the cultural requirements of economic life. Again, Gellner:

For the first time in human history, explicit and reasonably precise communication becomes generally, pervasively used and important. In the closed local communities of the agrarian or tribal worlds, when it came to communication, context tone, gesture, personality and situation were everything (33)

Communication "by means of written, impersonal, context-free to-whom-it-may-concern type messages" required what Gellner termed "exo-education", that is, childhood socialization by specialists who are not members of one's family or group of close associates. Paradoxically, he wrote,

...industrial society may ..be the most highly specialized society ever: but its educational system is unquestionably the least specialized, the most universally standardized, that has ever existed. (27)

This was the process that, in Eugen Weber's phrase, turned Peasants into Frenchmen (Weber (1976)) and villagers into citizens around the world wherever nationalism took hold. In many cases, far from being the expression of a unified culture, states preceded 
the emergence of a nation. Taparelli D'Azeglio (1867) had served as prime minister of Piedmont; writing about his country's unification he observed "Italy has been made Italy, but not the Italians."

The absorption of local agrarian idioms and symbols into a standardized national culture would have been resisted more forcefully had it not provided important benefits for those making the transformation Though Gellner did not stress this, exo-education in a common language and culture is a form of risk reduction, for it gives the exoeducated individual general skills that may be deployed in a variety of pursuits rather than the occupation- or sector-specific skills that were passed on by parents engaged in the forms of endo-education typical of agrarian societies. ${ }^{3}$

To see this suppose that uncertainty takes the form of the occurrence of either a status quo state, in which the individual continues his current livelihood with income $y$, or a bad state in which there is no demand for individual's particular line of work, and he is thus must pursue some other livelihood in which he receives $y(1-s)$ where $s$ is a measure of the degree to which his skills are specific to the initial livelihood. Suppose the status quo occurs with probability $p>1 / 2$.. The individual's expected income is

$$
\mathrm{E}(y)=p y+(1-p) y(1-s)
$$

and the variance of his realized income is $p(1-p)(y s)^{2}$.

The structural and technical dynamism of capitalism arguably lowered the probability of the status quo, but exo-education also lowered $s$. Because of cultural homogenization coupled with the spread of mass exo-education, investments in human capital became more general and (in bad states) more easily deployed in alternative uses In the process of creative destruction, successful creation was now greatly remunerated while, at the same time, the costs of destruction and failure were substantially decreased by the increased reversibility and liquidity of human skills.

If the emergence of mobility and markets required some minimum degree of cultural homogenization, their development also implied a dramatic further increase in cultural homogenization that, in most cases, caused a deepening of the feelings of national solidarity. Cultural homogenization and solidarity within large well defined territories are, thus, two complementary aspects of nationalism. At the same time, they are also substitutes in the sense that they can acts as alternative insurance devices against the risk associated to the specialization of skills in a volatile market society (D'Antoni and Pagano (2002)).

${ }^{3}$ The role of schooling in facilitating relationships among non-kin and even strangers is the central argument of Dreeben (1967) 
While the national state originated this self-reinforcing process, it could hardly be contained forever within the boundaries of national states. Some national states developed a sense of "global mission" and started doing to other languages and traditions what the national state had done to the diverse cultures and dialects within its boundaries. Included are Britain with its Commonwealth, the Russian Empire in its last manifestation as the Soviet Union, and United States with its federal system, with its frontier and with its melting pot of different ethnic groups.

In many cases, national states -- especially the non-English speaking ones - now find themselves in opposition to the further advancement of the very process of cultural homogenization that a century earlier had been their main task and, perhaps, the fundamental reason for their existence. The former cultural standardizers of the Age of Nationalism have become the victims of standardization on an even grander scale, a historical nemesis that threatens the survival of their own traditions. The energetic defense of the French language and the ongoing battles within the World Trade Organization about national subsidization of cultural production reflect this development.

\section{Cosmopolitans and Provincials}

This is the sense in which we mean that globalism is the highest stage of nationalism. But the emerging global world order marks a new age, as different from the nationalisms with which now contends as from the ancient empires with which it is inevitably compared.

It is different from the empires that had in the past politically unified large areas of Europe, Northern India, and even China. The Roman Empire of antiquity and, after that, the Holy Roman Empire never posed a comparable challenge to cultural diversity. The universal culture and the lingua franca remained the distinctive mark of the ruling classes. The same could be said with only slightly less force of the Mughal Empire. In the ancient empires, a modicum of political unity was accomplished in the absence of cultural unity. Globalization appears likely to do the opposite.

Modern globalization spreads global culture well beyond a ruling minority. But while the economic integration and cultural standardization accomplished by globalization may favor greater political integration, political unity today is mainly based on the dominance of United States, on local process of political integration such as the European Community, and on the limited governance of some international institutions.

In addition to its lack of well defined boundaries, the nature of modern globalism is also fundamentally different from nationalism. The political unity of the national state made possible a distinctive method of risk reduction: cultural homogenization and social 
protection combined to reduce the risks associated with the market economy. Tax and transfer policies that redistributed income from the lucky to the unlucky decreased risk exposure, while those workers who had acquired job-specific skills were buffered from the vagaries of the labor market by employment safeguards and unemployment insurance. The willingness of the lucky pay to insure the unlucky even after the dice had been rolled was enhanced by the feeling that "it could have been me," itself a product of cultural homogenization.

Modern globalism not only lacks the international institutions allowing social protection on a world scale, it also makes the traditional forms of social protection offered by the national state increasingly problematic. The increased mobility of capital and other factors of production owned by the relatively well off has provided a rationale for shifting taxation away from these factors, thus raising the cost of policies designed to redistribute income within the nation state. ${ }^{4}$ Increasingly competitive goods markets, along with greater mobility of capital and professional labor has also reduced the scope for trade union bargaining (Choi (2004)) and in some countries weakened job protection.

Moreover, cultural standardization-- the other instrument by which national economies have traditionally insured their citizens against the risks of market mobility -is very limited in the internationally integrated economy. Access to the dominant cultural standard - English fluency -- is much more unequally distributed on a world scale that the national equivalents within national boundaries - fluency in the national language. The result is a division between those endowed with mobile intellectual assets that are easily redeployed throughout the global economy - the cosmopolitan s - and those that have skills that are less mobile and more specific to the national economy -- the provincials. The distinction, roughly, that is between the skills typical of people working in Silicon Valley and Detroit, or Bangalore and Kanpur.

Cosmopolitians -- even those with modest incomes -- may prefer to replace social protection with cultural standardization as their preferred form of insurance, withdrawing where possible from the mutual insurance system that characterizes national states. Like financial capital, these workers may become difficult to tax. Their relatively easy exit from a national system of mutual insurance makes it even more difficult to finance the traditional forms of social protection supplied by the national state and worsens the situation of those workers who lack access to the global cultural standard.

The partial cultural standardization associated with modern globalism may thus create a world cosmopolitan elite communicating amongst themselves in a new Latin that cannot be used as a working language by the vast majority of the populations among

${ }^{4}$ We say "has provided the rationale" because the evidence that own-country investment is more sensitive to tax differentials among nations than previously is thus far lacking. 
whom they live. The result would be an information-age equivalent to the old agrarian societies studied by Gellner, presided over by an elite whose high culture unites them around the globe as it separates them from the rest of their own societies, who are in turn separated one from another by the persistence of linguistic and cultural divisions. The fact that many workers of modest incomes will count themselves among the cosmopolitans differentiates modern globalism from the ancient agrarian societies and empires. But, as we will se, this may also exacerbate the challenge facing the nationally based welfare state.

\section{The Politics of Insurance}

To show this, we will model the social insurance preferences of a citizenry of identical decreasingly risk averse individuals. Preferences among citizens are identical but, due to differences in the nature of their income earning assets, they differ in expected income and risk exposure. ${ }^{5}$ If an individual's utility as a function of her income is $U=U(y)$ then the Arrow-Pratt measure of risk aversion is $\lambda=-U$ ' $/ U$ '. If the utility function is less concave at higher levels of income, or $\mathrm{d} \lambda \mathrm{d} y<0$, then decreasing risk aversion is said to obtain, meaning that the rich are less risk averse than the poor. ${ }^{6}$

While the concavity of the utility function undoubtedly captures important aspects of behavior in the face of risk, it certainly misses important influences such as aversion to uncertainty, ambiguity, and fear of the unknown. We therefore use a framework in which the concavity of the utility function as but one of many reasons a citizen may wish to avoid risk. The approach captures the Arrow-Pratt logic under appropriate conditions, but is not restricted to it. The basic idea is that expected income as a "good" and the variance of income as a "bad." Social insurance is a way of reducing one's exposure to the bad by trading away some of the good.

Suppose the income $y$ of an individual with a given set of assets income varies in response to stochastic shocks according to

$$
y=z \sigma+g
$$

${ }^{5}$ We are here following the work of Sinn (1995) and Domar and Musgrave (1944)) who modeled the welfare state as a process of redistribution from the lucky to the unlucky rather than from the rich to the poor. Our model is an adaptation of D'Antoni and Pagano (2002). Contrary to compelling evidence of widespread fairmindedness and concern for the less well off even among higher income earners (e.g.Fong (2001)), we assume that our citizens are entirely self regarding.

${ }^{6}$ Evidence that risk aversion is decreasing in income is presented in Saha, Shumway, and Talpaz (1994) 
where $g$ is expected income and $z$ is a random variable with mean zero and unit standard deviation. Thus, $\sigma$ is the standard deviation of income, a measure of risk. Then we write the individual's utility function as

$$
v=v\{g, \sigma\}
$$

With suitable restrictions on its partial derivatives, this function expresses the individual's positive valuation of higher levels of expected income $\left(v_{g}>0\right)$ and negative valuation of more uncertain income $\left(v_{\sigma} \leq 0\right)$, without implying that the latter is due to the concavity of the function $U(y)$. Because of the particular way we have introduced risk, however, this function is also able to capture the logic of the Arrow-Pratt measure. ${ }^{7}$

The indifference loci representing an individual with decreasing risk aversion

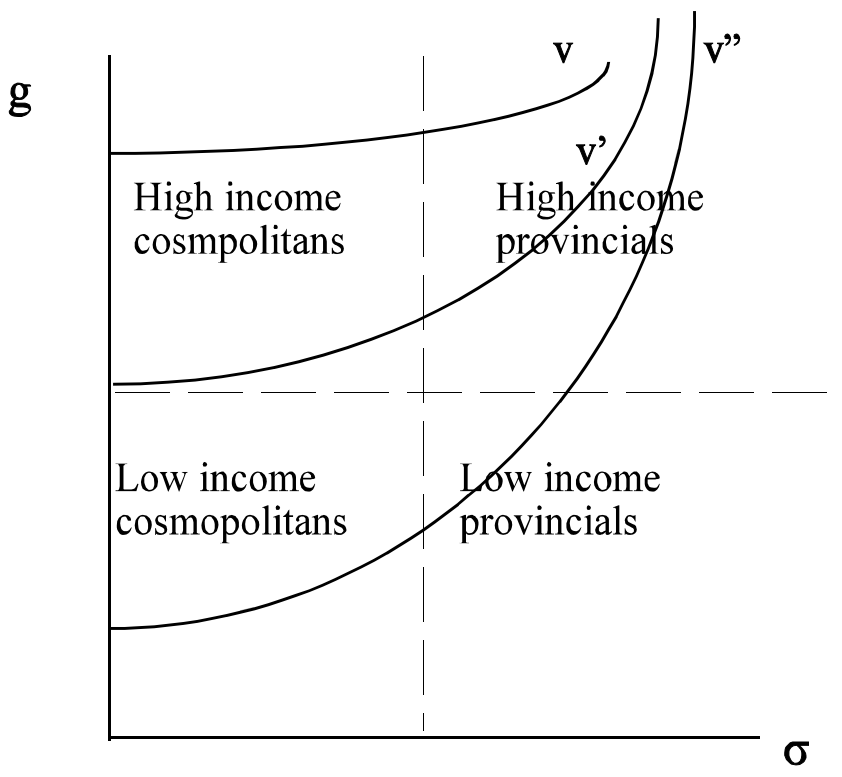

Figure 1. Indifference loci of a decreasingly risk averse citizenry with a taxonomy of citizens according to their assets and associated expected income and risk exposure.

${ }^{7}$ The general utility function $U(y)$ can be expressed as a simple two-parameter utility function in this case because the variation in income is generated by what is termed a linear class of disturbances. The technical details are in Bardhan, Bowles, and Gintis (2000), drawing on the earlier work of Meyer (1987) and Sinn (1990). 
appear in Figure 1. They are increasing and convex in $\sigma$, flat at the vertical intercept $\left(v_{\sigma}=0\right.$ for $\sigma=0$ ), become flatter for increasing $g$ when $\sigma>0$ and become steeper for increasing $\sigma$. The slope of an indifference locus, $-v_{\sigma} / v_{g} \equiv \eta(g, \sigma)$, is the marginal rate of substitution between risk and expected income. Thus $\eta(g, \sigma)$ is a measure of the level of risk aversion experienced by an individual faced with a given level of expected income and risk. It is clear that this measure of risk aversion is increasing in the level of risk exposure (movements to the right in Figure 1) and decreasing in the level of expected income (movements upwards in Figure 1).

Figure 1 also indicates the $\{\sigma, g\}$ pairs associated with four classes of citizens demarcated by their income levels and risk exposure.

Now suppose the citizens may tax themselves at a rate $t$, paying to each citizen an equal share of the proceeds of the tax, $t y^{o}(1-w)$, where $y^{o}$ is mean income and $w$ is the proportional loss in distributed benefits due to administration, deadweight losses, capital flight or other costs of operating the system. The citizen's post-tax and transfer expected income is now:

$$
g^{t}=g(1-t)+t y^{o}(1-w)
$$

and its standard deviation, $\sigma^{\mathrm{t}}$, is $\sigma(1-t)$.

Varying $t$ affects both expected income and the standard deviation of income. The effect on expected income (differentiating (4) with respect to $t$ ) is $-\left\{g-y^{o}(1-w)\right\}$ and the effect of variations in $t$ the standard deviation of income is $-\sigma$. Thus for $\sigma>0$ this "insurance technology" implies a "price of insurance," $\rho$, namely the loss in expected income associated with a reduction in risk exposure, or what may be termed the marginal rate of transformation of expected income into risk reduction. This price is just the ratio of the two effects of varying $t$ so

$$
\rho=\left\{g-y^{o}(1-w)\right\} / \sigma
$$

If she could unilaterally determine the tax rate, the citizen whose expected income is less than $y^{o}(1-w)$ could "purchase" insurance at negative cost (i.e. $\left.\rho<0\right)$, benefitting from both the risk reduction and the fact that her transfer will exceed her tax payment. The price of insurance is increasing in expected income and declining in risk exposure, as one would expect.

What tax and transfer level would citizens prefer, if they were in position to determine $t$ ? A citizens with $g>y^{o}(1-w)$ would maximize expected after-tax and transfer utility, $v^{\mathrm{t}}=v\left\{g^{\mathrm{t}}(\mathrm{t}), \sigma^{\mathrm{t}}(\mathrm{t})\right\}$ by selecting the value of $t$ that equates the price of insurance (the marginal rate of transformation of expected income into risk reduction) 
to the marginal rate of substitution between risk and expected income, i.e. $\rho=\eta$. In figure 2 this optimum is point a for a person whose assets placed her at a'.

A person whose assets placed him at point $\mathbf{f}$, better off than at point $\mathbf{a}$ ' and no more risk exposed, would prefer a tax rate of zero (if he could, he would happily run the tax system in reverse, setting $t<0$ and with all citizens paying a given lump sum in return for a linear subsidy of their earnings, but we will not consider this case). Thus, we can divide the citizenry into two classes: those whose asset position yields a positive optimal tax rate, and those who would prefer no social insurance.

We know that an individual with no risk exposure $(\sigma=0)$ and $g=y^{o}(1-w)$ will be indifferent to the choice of $t$, for it will affect neither his risk exposure nor his expected income. Now consider a person for whom $g$ exceeds $y^{o}(1-w)$ by a small amount. If the person is not risk- exposed, he will oppose social insurance; but there will be some level of risk exposure that will make him indifferent between no tax and a positive tax rate, namely that for which $\rho=\eta$. The $(g, \sigma)$ pairs for which $\rho=\eta$ form the zero tax locus in figure 3 . Those whose assets place them above the zero tax locus will oppose social insurance, while those below it will support some level of taxation.

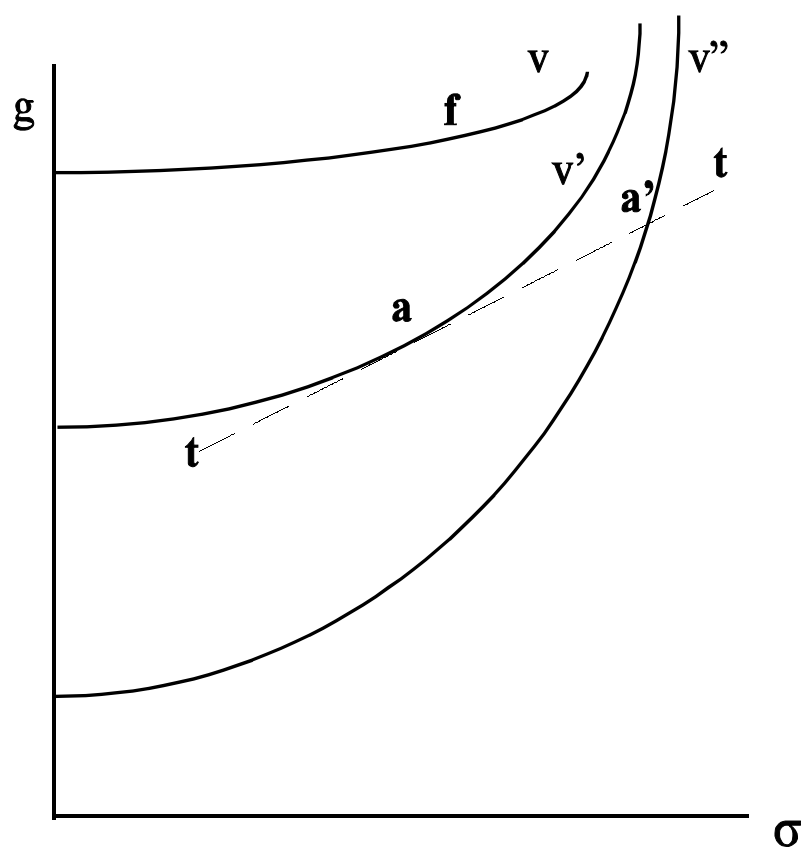

Figure 2. A citizen's optimal level of insurance. The person with assets which the absence of insurance would yield the outcome at a' prefers to purchase insurance at the price indicated by the slope of the "insurance technology" locus, tt. 
This view of voter preferences receives support from a study by Iversen and Soskice (2001). They estimated the relationship between support for redistributive measures and the degree of specificity of an individual's skills in two social survey data sets in 11 advanced democracies in the late 1990s. Conditioned on other influences on political preferences (income, sex, employment status, party affiliation, and age) the degree of skill specificity is a highly significant determinant of support for redistributive policies, equal in effect size to income (that is a standard deviation difference in skill specificity is associated with a difference in redistributive preferences an equivalent in size to a standardization deviation difference in income.)

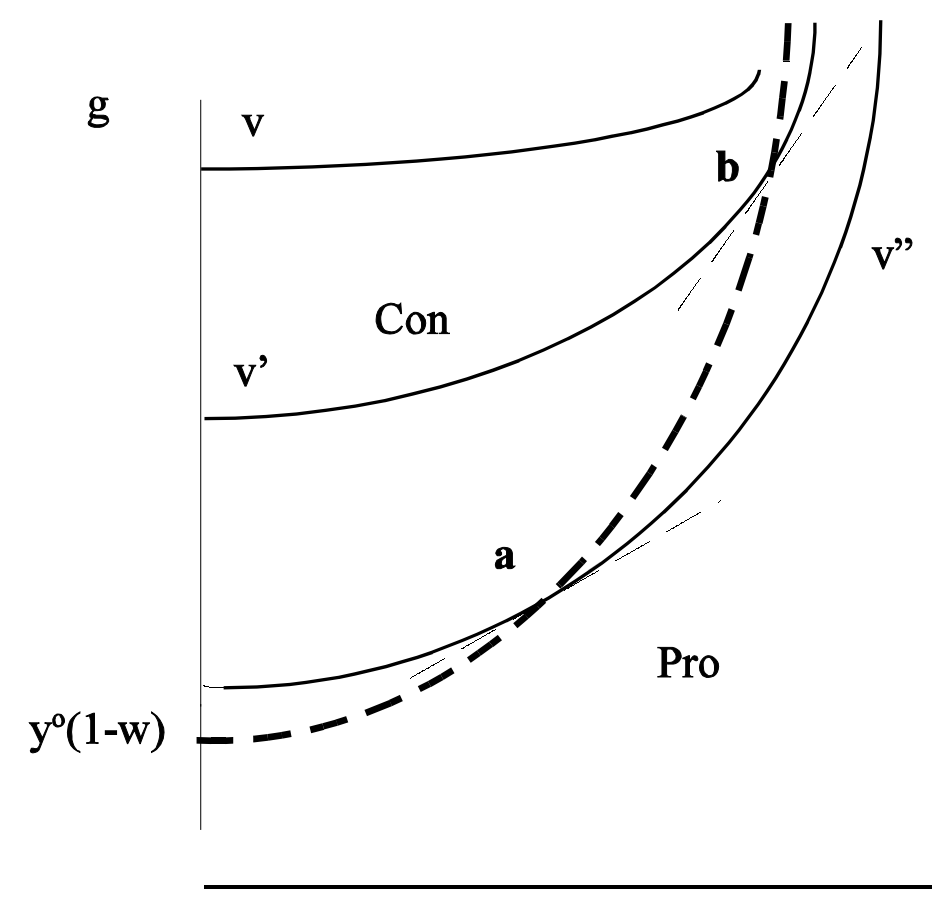

Figure 3. Social insurance: Pro and con Individuals whose assets place them at points a or b favor zero social insurance. Individuals above and to the left of $\mathbf{a}$ and $\mathbf{b}$ oppose social insurance. The zero tax locus --the heavy dashed line -- is the locus of all such points. Thus those above the zero tax locus oppose social insurance; those below it support it 


\section{Globalism vs the Welfare State?}

Consider three effects of globalism. First, the costs of redistribution may increase. In our model this is just an increase in $w$, which (from (5)) has the effect of raising the price of insurance, increasing the slope of the tt locus in figure 2 and thereby shifting the zero tax locus downwards. As a result more citizens are included in the con rather than the pro classes.

Second, if economic integration raises incomes (as one may expect it to do on average), it will move citizens upwards in figure 3 , leading to reduced support of the welfare state.

Third, globalism may alter the distribution of citizens in $\{g, \sigma\}$ space. Rodrik (1998), Garrett (1998) and others have suggested that openness may increase support for the welfare state by increasing risk exposure (shifting voters to the right in figure 3.) These effects appear to have been at work in a number of countries, including those that pioneered the institutions that we now call the welfare state (Moene and Wallerstein (1995). ${ }^{8}$

While we believe these effects to be operative in many cases, we have above stressed another possible shift in the distribution of citizens: the emergence of a large class of cosmopolitans, including many with middling incomes. To dramatize the importance of this shift (through a bit of exaggeration), consider a "prototype $19^{\text {th }}$ century economy". It is composed of what Alchian and Demsetz (1972) called "classical capitalist firms" whose single owner hires (in a daily spot market) workers with few firm-specific skills (what Marx termed abstract labor). An owner of tangible assets in such a firm is highly risk exposed, as there is a substantial loss in the value of an asset once it is the installed - in the modern economy typically well over half of the initial cost (Asplund (2000)). By contrast, the workers' job assets - abstract labor - make them much less risk exposed. In this world, the owners would be classed among the high income provincials in figure 1 , while the workers would be the low income cosmopolitans: the distribution of citizens would lie in the "north east" and "south west" quadrants. Of course most workers' expected incomes would be such that $g<y^{o}(1-w)$, so most workers and all but the very rich owners would support the welfare state.

This economy is imaginary, but the contrast between it and what may be the emerging global order is striking. Workers now receive substantial job rents, that is, pay above their next best alternative. These are the result either of workers' firm-specific skills, or of the widespread use by employers of contingent renewal strategies of labor

${ }^{8}$ The study by Iversen and Cusack (2000) of the sources of welfare state expansion in the advanced countries finds that technology shocks and structural transformations of the economy unrelated to globalization have larger effects. 
discipline that result in equilibrium wages in excess of workers' reservation wages. And while industrial assets are still highly specific, many of the assets used in the sales and service sectors of the economy (far larger than manufacturing in most advanced economies) are quite general (buildings and computers, for example). Moreover, in contrast to the fictive classical capitalist firm, ownership of these assets is highly diversified. Both diversification and the more general nature of these assets have the effect of greatly reducing risk exposure. Additionally, there is now a large class of salaried employees whose high level of general skills, including their access to the global cultural standard, greatly reduces their risk exposure. These are the new cosmopolitans.

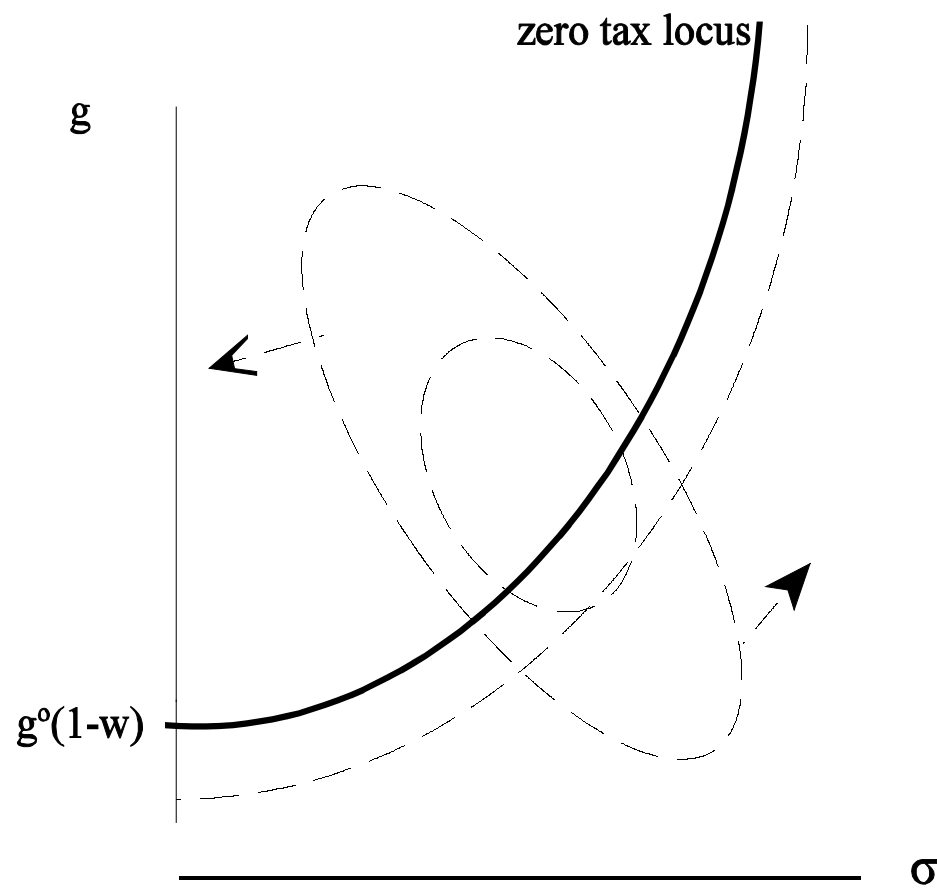

Figure 4. Changing distribution of citizens and zero tax locus under the influence of globalization. The dashed contours give the distribution of voters. The dashed zero tax locus shows the effect of the increased price of insurance.

Figure 4 illustrates these shifts. The inner dashed contour indicates a greater density of citizens, and the increasingly "north-west, south-east" array of citizens suggests a new dimension of support and opposition for social insurance, namely the degree access to the global cultural standard. One cannot rule out a "twin peaks" distribution emerging, with a concentration of well-to-do cosmopolitans and less well off provincials divided by a ravine of cultural disparity and divergent economic opportunity. To avoid unnecessary simplification, we have deliberately not specified 
how the national tax rate will be selected. So one cannot predict the effect on the amount of support for social insurance in general.

This is especially the case because the process of economic integration is also one of specialization, the effect of which is that countries will become more distinct in the kinds of skills and other assets that their product mix requires. Suppose there are two goods, grain and plows, and that in the absence of international exchange each of two countries would employ equal numbers of worker-citizens producing the two goods. The demand for plows, as an investment good, is highly volatile (it is proportional to the change in the level of demand for grain), while the demand for grain, a consumption good, is less volatile, depending on the level of income and population. Except for the very well paid, those employed producing plows will be supporters of insurance, while except for the poorest, those growing grain will oppose it. Many models of the process electoral competition would predict that the resulting social policy would include some but not very much social insurance.

Following economic integration, however, one country specializes in plow production and the other in grain production. As a result, the voters in Ploughland are now almost uniformly supporters of social insurance, while the citizens of Grainia are equally opposed (unless, of course, openness has increased risk exposure in Grainia sufficiently to offset the reduction in risk associated with specialization in the less volatile good). The result is that economic integration may lead to greater institutional diversity, rather than, as is sometimes predicted, institutional homogenization.

Only slightly less transparent is the case where sectors differ in the importance of specific skills, and integration leads to some countries specializing in producing general-skill goods and others in specific-skill goods. This view is advanced by Hall and Soskice (2001):38. “...national institutional frameworks provide nations with comparative advantage. In the presence of trade, these advantages should give rise to ...specialization." In turn, according to Hall and Soskice, specialization in those goods for which a country has a comparative advantage is likely to support institutional divergence.

In theses cases, the specialization associated with integration may enhance the diversity of 'technology-institutional equilibria'(Pagano, Ugo (1993)). Hall and Soskice have interpreted the differing social policies of the U.S. and Germany in this light, the German product mix requiring high levels of specific skills, the protection of which through generous unemployment benefits and other forms of job protection is supported by large majorities of the public. The presence of these social protection policies, in turn, allows these specific skill intensive industries to attract labor and remain viable in international competition. 
The presumption that globalism induces institutional convergence is based on a simple, but wrong model. Global competition is represented as a kind of selection pressure operating to force the elimination of inferior designs. But geography and history combine to make specialization advantageous, and given that some institutions are better able to coordinate the production of some goods, while other institutions do better for other goods, the increase in selection pressure may produce divergence rather than convergence (Pagano, Ugo (2001). It was economic integration - not autarky that induced the divergence in institutional structure between the sugar growing islands of the Caribbean on the one hand, and those economies of Central America, such as Costa Rica, whose geography is ill suited to plantation crops. ${ }^{9}$ Another example: the importance of family owned firms in the Italian economy distinguishes it from most of its competitors, and is in turn explained by the fact that due to economic integration, Italy increasingly specializes in those goods for which this form of governance is effective.

To the extent that some policies of social insurance are indeed simply inferior designs, while other nation's lack of social insurance are also simply flawed designs, globalism will increase the pressures for policy convergence. But one cannot say if these forces will be offset by the persistence of distinct institutional arrangements associated with high levels of specialization.

\section{Optimal Specialization?}

Investment in general rather than industry- or occupation-specific skills and assets is a means of reducing risk exposure, and thus may be a substitute for the kinds of social insurance modeled above. What may be termed a cosmopolitan risk reduction strategy may become increasingly attractive in those countries in which economic integration creates pressures to reduce the scope of social insurance and job protection. But, unless emigration is a feasible option, even those with general assets are vulnerable in an economy specialized in the production of a limited range of goods. This is because the protection against adverse price shocks offered by general assets takes the form of an ability to redeploy these skills in other industries or occupations for which the relevant prices are substantially uncorrelated. The shock-induced relocation of inputs from one industry to another will generate adverse price effects even when assets being relocated are entirely general. But in an economy with a diverse "portfolio" of industries and occupations, these effects will be small as long as the adversely affected sectors are small relative to the size of the economy as a whole.

${ }^{9}$ Ortiz (1963) describes the correspondence between the nature of agricultural crops - tobacco and sugar - and the institutions governing their production in preRevolutionary Cuba. 
The existence of such a diverse "portfolio" of industries and occupations is, however, a public good in the sense that it provides general risk-reduction benefits that are not accounted for in the individual's utility- or profit-maximizing choices concerning occupational or sectoral location. For this reason economies guided entirely by private incentives will tend to overspecialize. Global economic integration will exacerbate this market failure if it increases risk exposure and reduces the scope of substitute forms of risk reduction such as social insurance. (We have given reasons above to doubt that these widely presumed effects of globalization will be uniformly experienced among nations.)

\section{Conclusion}

If we are correct, understanding the impact of globalism on national policies for redistribution and social insurance would be enhanced by greater attention to the degree of specificity of the assets held by people and to the possible emergence of a large class of cosmopolitans with little interest in traditional social insurance policies and weak solidarity with co-resident provincials. It would be valuable to know, as an empirical matter, if among people with similar incomes those with more general education tend to oppose social insurance. Equally important is the possible divergence of national institutional trajectories as a consequence of more advanced levels of specialization made possible by global integration. Are there empirical cases in which divergence in social insurance policies can be plausibly linked to divergent patterns of specialization following economic integration?

Our approach also suggests some interesting puzzles. Why, for example, are the children of the relatively well off the cosmopolitans, while the children of less well off tend to become provincials? Given the greater risk aversion of the latter group (parents and children alike), one might have expected the reverse. Of course in most countries, the types of education experienced by the two groups differ, with the cosmopolitans more likely to gain a classical liberal arts education including languages, while the latter acquire occupational skills. But there is a substantial element of choice involved in implementing this difference. Are the general skills of the cosmopolitans complementary with wealth, so that the asset poor benefit less from learning English, or programming skills, for example, than the children of the well to do? Another intriguing puzzle would be to understand one of the few effective political coalitions across the provincialcosmopolitan divide, namely the anti-globalization movement in Europe and North America. 


\section{Works cited}

Alchian, Armen A. and Harold Demsetz. 1972. "Production, Information Costs, and Economic Organization." American Economic Review, 62:5, pp. 777-95.

Asplund, Marcus. 2000. "What fraction of a capital investment is sunk costs?" Journal of Industrial Economics, XLVIII:3, pp. 287-303.

Bardhan, Pranab, S. Bowles, and H. Gintis. 2000. "Wealth Inequality, Credit Constraints, and Economic Performance," in Handbook of Income Distribution. Anthony Atkinson and Francois Bourguignon eds. Dortrecht: North-Holland, pp. 541-603.

Bardhan, Pranab, S. Bowles, and Michael Wallerstein. 2004. Globalization and Redistribution. New York: Russell Sage Foundation.

Choi, Minsik. 2004. "The Threat Effect of Capital Mobility on Wage Bargaining," in Globalization and Redistribution. Pranab Bardhan, Samuel Bowles and Michael Wallerstein eds.

D'Antoni, M and Ugo Pagano. 2002. "National Cultures and Social Protection as Alternative Insurance Devices." Structual Change and Economic Dynamics, 13, pp. 367-86.

D'Azeglio, Taparelli. 1867. I miei ricordi. Torino.

Domar, Evsey and Richard A. Musgrave. 1944. "Proportional Income Taxation and Risk-Taking." Quarterly Journal of Economics, 58, pp. 388-422.

Dreeben, Robert. 1967. On what is Learned in School. Reading, MA: Addison-Wesley.

Fong, Christina. 2001. "Social preferences, self interest and the demand for redistribution." Journal of Public Economics, 82:2, pp. 225-46.

Garrett, Geoffrey. 1998. Partisan Politics in the Global Economy. Cambridge: Cambridge University Press.

Gellner, Ernest. 1983. Nations and nationalism. Ithaca: Cornell University Press.

Gellner, Ernest. 1998. Nationalism. London: Phoenix. 
Gellner, Ernest. 1999. "The coming of nationalism, and its interpretation: The myths of nation and class," in The politics of exchange and economics of power. S Bowles, M. Franzini and U. Pagano eds. London: Routledge, pp. 179-225.

Hall, Peter and David Soskice. 2001. Varieties of Capitalism: The Institutional Foundations of Comparative Advantage. Oxford: Oxford University Press.

Iversen, Torben and Thomas Cusack. 2000. "The causes of welfare state expansion: deindustrialization or globalization?" World Politics, 52, pp. 313-49.

Iversen, Torben and David Soskice. 2001. "An asset theory of social policy preferences." American Political Science Review, 95:4, pp. 875-93.

Kindleberger, Charles P. 1969. American Business Abroad: Six Lectures on Direct Investment. New Haven: Yale University Press.

Meyer, Jack. 1987. "Two-Moment Decision Models and Expected Utility." American Economic Review, 77:3, pp. 421-30.

Moene, Karl Ove and Michael Wallerstein. 1995. "How Social Democracy Worked: Labor-market Institutions." Politics and Society, 23, pp. 185-212.

Ortiz, Fernando. 1963. Contrapunteo Cubano del Tabaco y el Azucar. Barcelona: Editorial Ariel.

Pagano, U. 2003. "Nationalism, Development, and Integration: the Political Economy of Ernest Gellner." Cambridge Journal of Economics, September.

Pagano, Ugo. 1993. "Organizational Equilibria and Institutional Stability," in Markets and Democracy: Participation, Accountability and Efficiency. S. Bowles, H. Gintis and B. Gustafsson eds. Cambridge: Cambridge University Press.

Pagano, Ugo. 2001. "The Origin of Organizational Species," in The Evolution of Economic Diversity. Ugo Pagano and Antonio Nicita eds. London: Routledge.

Rodrik, Dani. 1998. "Why do open economies have larger governments?" Journal of Political Economy, 106.

Saha, Atanu, Richard C. Shumway, and Hovav Talpaz. 1994. "Joint Estimation of Risk Preference Structure and Technology Using Expo-Power Utility." American Journal of Agricultural Economics, 76:2, pp. 173-84. 
Sinn, H. W. 1990. "Expected Utility, mu-sigma Preferences, and Linear Distribution Classes: A further Result." Journal of Risk and Uncertainty, 3, pp. 277-81.

Sinn, H. W. 1995. "A Theory of the Welfare State." Scandinavian Journal of Economics, 95:4, pp. 495-526.

Weber, Eugen. 1976. Peasants into Frenchmen: The Modernization of Rural France, 1870-1914. Stanford: Stanford University Press. 